\title{
TEACHERS`SUPPORT SERVICE AS A PART OF FLEXIBLE EDUCATION CONCEPT: EXPERIENCE OF PR CHINA
}

\author{
Lyubov Kalashnyk \\ H.S. Skovoroda Kharkiv national pedagogical University, Ukraine \\ Oksana Mkrtichan \\ H.S. Skovoroda Kharkiv national pedagogical University, Ukraine \\ Kostiantyn Zhukov \\ Kharkiv Medical Academy of Post-graduate Education, Ukraine \\ Andrey Marakushyn \\ Simon Kuznets Kharkiv National University of Economics, Ukraine
}

\begin{abstract}
In 2020 China became the first country of the world that faced all the challenges of the COVID-19 pandemic, including the ones that dealt with education. They were the first ones to provide lock-down and distance education as the only education reality as well as the first ones to face all the positive and negative repercussions of the process mentioned. That's why the Chinese experience (both negative and positive) is worth presenting and exploring. There is one more peculiarity of the Chinese educational system that makes it unique and lets the country in a short period make a distance education system became competitive with the traditional off-line one. It is a teachers `support system that includes not only the teachers training system (vocational training activities), but also financial support for using different onlineeducation tools, direct assistance of a group of specialists during preparing and lessoning, psychological support etc. The study aims to present the positive educational and organisation experience already approved in China. When writing the article, methods such as observation, study of normative and scientific literature were used for a comprehensive analysis of the new pedagogical reality - the teachers `support service.
\end{abstract}

Keywords: knowledge; education; flexible education; teacher; teachers` support service; online education; regular (off-line) education.

\section{Introduction}

The idea of providing educational services in a distance form (not classroom one) is not new, but has been permanently developed and tested by practitioners of educational activities since the middle of the 19th century, when in 1840 Sir Issac Pitman (Great Britain) offered his students cursive and English courses by mailing. With the advent of computers, a new era has begun in the very concept 
of education and its tasks, methods, principles, practical approaches, and the Corona-19 pandemic has intensified this process at times. There happened a ualitative breakthrough (not the evolutionary, but the revolutionary one) not only in the practice of providing educational services, the rapid development of related areas of activity (IT technologies to ensure the educational process, communication tools, appearing a huge amount of constructors for conducting classes, programs for monitoring the quality of educational and teaching activities, etc. ), but also a revision of the education systems tasks, social and state requirements both to the process and to the result of education systems activity, strengthening of motivational and self-regulatory components in obtaining knowledge, etc. (Baroutsis et al., 2020).

But, unfortunately, most of the theoretically positive innovations in online education face teachers ' unreadiness and unwillingness to perceive and use them. To solve this problem, countries use methods and ways that are most consistent with their historical and pedagogical experience, pedagogical traditions, current level of IT technologies` development and financing in each particular country. The most popular method is self-education of teachers and / or the urgent creation of a system for improving the qualifications of teachers (especially as to IT technologies) through trainings, lectures, webinars, etc. (Joan, 2013). We want to emphasize that we are talking about working teachers (those who are engaged in educational practice now) and the problem of their IT qualifications and skills gained should be solved as soon as possible in order to continue the high-quality educational process online. We are not talking about teachers-to-be and about the issues of including / strengthening of IT training component in the standard educational programs of special and higher pedagogical educational institutions and vocational training programs for teachers.

The uniqueness of the Chinese approach to solving this problem lies in the fact that at the state level a system of support and consultation of working teachers was created. This system from the technical point of view should accompany the online teaching process, since most teachers who work in the education system of the PR China and are in the age period of 40+ are practically and psychologically not ready to use such an amount of IT and ICT technologies, that are involved in the modern process of online education, and their retraining will take a long time. The Chinese see Teachers` support service as a mandatory part of online and distance education process that is already reflected in the Flexible Education Concept adopted by the Chinese government in February 2020. 
SOCIETY. INTEGRATION. EDUCATION

Proceedings of the International Scientific Conference. Volume V, May $28^{\text {th }}-29^{\text {th }}$, 2021. 116-126

\section{Literature Review}

The basic source of information on the creation and functioning of the teacher support system during the COVID-19 period was the scientific development of such Chinese scientists as Zhonghuai Huang (professor of the Education Department at Beijing Normal University), Dejiang Liu (co-dean of the Institute of Smart Learning, Beijing Normal University), Changjie Chen (deputy Dean, Institute of Smart Learning, Beijing Normal University), Haijun Zeng (Head of the Administrative Department of the National Engineering Laboratory for Machine Learning and Digital Technologies of the People's Republic of China), Junfeng Yang (Professor of the College of Education, Hangzhou Pedagogical University), Rongxia Zhuang (Assistant Professor of the Education Department at Beijing Normal University), Tingwen Chan (Deputy Dean of the Smart Learning Institute of Beijing Normal University), etc. In February 2020, they developed a "Handbook on Facilitating Flexible Learning During Educational Disruption: The Chinese experience in Maintaining Undisrupted Learning in COVID-19 outbreak» (Beijing, 2020) which has received the approval of the state and since March 15, 2020 is considered the state strategy for building out the online education process in the crisis period for the PR China in particular. This publication received a recommendation from UNESCO International Research and Training Center for Rural Education Development and is presented in the international arena as the official position of the Chinese state on the problem indicated.

The publication reflects such issues as what is "flexible learning" in the context of the suspension of the educational process (including the very concept of "flexible education" taking into account the Chinese cultural, social and educational realities today, the characteristics of flexible education, the parameters of flexibility in education), the organization of online education to ensure flexible education (using IT technologies in education, the concept and features of online education during a social crisis, forms of providing online education), the development of the network infrastructure of online education in the context of "flexible education", the principles of assessing the target correspondence of digital educational resources to the tasks of the education system in a specific period of time, ways to ensure the effectiveness of online teaching and learning (including the systematic organization of education, social aspects of organizing educational activities, support and services for teachers and students), cooperation of government agencies`, private companies`and educational institutions`cooperation to maintain and develop the effectiveness of the educational process and others.

To analyse the problem of ICT and IT as a part of teachers support service in China we used the works of the Chinese educators as well as of the abroad ones that reflect different issues of the problem mentioned starting from the general 
prospects of the ICT development as an educational and practical method for the Chinese teachers (Ding Bo; Kuai Milan; Liu Xian) etc. and up to general prognosis of ICT development in China as a teaching and method and aim of the Educational Paradigm for the century coming (Wan Yi; Zhu Zhijing, Gu Xiaoqing, Collis Betty, Moonen Jef) and others. Some of the modern publications on the issue reflect main difficulties China faces in ICT development (Miao Fengchung, Trucano Michael).

\section{Methodology}

In the process of writing, the authors used methods and techniques typical for scientific research in the field of social pedagogy and theory of education:

- general scientific methods (analysis, generalization, comparison) for analysis and research work with encyclopedic, psychological, pedagogical and methodological literature on the subject of research. The designated reality (teachers` support as a practical system that is initiated by a state) today exists in the form of social and pedagogical practice only and requires reflection on the basis of the methods and approaches available in the pedagogical theory.;

- problem-targeted methods for the analysis of scientific and methodological literature, periodicals and normative documents related to educational process for teachers organization in both pedagogical and non-pedagogical education institutions of China. The use of this approach made it possible to identify the contradictions between the high level of the Chinese pedagogical practice development, the country's active participation in the implementation of pedagogical strategies and its quick reacting to the changing reality (in the educational sphere as well) and a rather low level of theoretical support of this process the Chinese and foreign scientists;

- comparative pedagogical methods for analyzing and research study in using and treating organization issues of filling gaps by teachers in the use of ICT and IT technologies in the process of practical online education (as well as the method of self-education of teachers and teachers-to-be) and one of aims of vocational training system for teachers and educators in China;

- $\quad$ hypothetical-deductive method was used to review the factual material aimed at analyzing the PR China`s government practice of organizing support for teachers' practical work through increasing the number of support staff (China's experience in this field is unique today), and also 
let the authors predict the psychological and social consequences of this initiative on the basis of existing in modern pedagogy theories and laws;

- method of pedagogical observation (through informal communication with teachers from China, who work in the system of school and university education, and the implementation of the Project " 1 teacher 2 classrooms", which is implemented through online learning tools (ZOOM) between the Department of Oriental Languages H.S.Skovoroda Kharkiv National Pedagogical University (Kharkiv, Ukraine) and Zhejiang Shuzhen University (Hangzhou city, Zhejiang province, PR China) ) to study the realities of teachers everyday work in the education system of China during the flexible education period caused by the COVID-19 lockdown.

While working over the article, research methods related to conducting a pedagogical experiment or approbation of a pedagogical idea were not used, since the purpose of the article is a comprehensive presentation of a new pedagogical reality for its further consideration and study.

\section{Results}

Research into the possibilities of flexible teaching and learning has a long history. "Flexibility" in this case is defined as offering a choice of educational formats, as well as adapting a specific curriculum to the needs of individual students and teachers. These choices may include the number of classes, course content, educational resources, methods and location of classes, information and communication technologies used, requirements for course start / end dates, and communication tools. Flexible learning process eliminates obstacles to certain formats of the educational process (for example, classroom), which may be inaccessible to students for many reasons (for example, natural disaster, pandemic, military and environmental disasters). As technology advances further, flexibility of teaching becomes a critical factor that usually allows two-way exchange of information between teachers and students. Gradually, the concept of flexible learning has expanded and now applies not only to teaching, but also to flexible pedagogy (Gordon, 2014; Ryan \& Tilbury, 2013). Gardon (2014) and Ryan \& Tilbury (2013) note that flexibility includes not only student choice, but institutional choice of educational strategy.

With the development of information and communication technologies, new educational models have emerged that have expanded the possibilities of flexible learning.Today as to the vocational training system of teachers China is actively building the infrastructure of specialized educational ICTs and ITs (the network of digital resources and educational innovations for teachers) and the management 
Kalashnyk et al., 2021. Teachers`support service as a part of flexible education concept: experience of pr China

of education system supported by ICTs. Teachers` education in the field of ICT and IT and high demands on a teachers `ability to use them are seen as a solution to many of China's current educational needs and problems. Also, according to the Chinese leadership, ICTs have high potential for expanding access to education in general and to teachers training and education system in particular. Ensuring fair and high-quality "electronic education" or using ICTs for teaching and learning in primary and secondary schools across the country is considered to be a national priority (Gu, Zhu \& Guo, 2013). At the same time, the development of using ICTs and ITs teaching and self-educating methods can exacerbate the existing digital and technological imbalance between urban and rural areas. While in Chinese cities about $80 \%$ of students use Internet at home for homework and self-study, in rural areas only $2 \%$ of school-age youth have Internet at home, and only half of them use it to communicate with a teacher or search for information necessary for educational process, etc. (Trucano, 2012).

Recently, teacher education institutes have made efforts as to integrating IT education component into their teachers-to-be educational programs. There were presented several key strategies to introduce IT integration to teachers-to-be: delivering a single technology course; offering mini-workshops; integrating the technology in all courses; modeling how to use technology, etc.

In the case of China, the government has given big emphasis to the effect of ICT and IT education integration, and dedicates to make ICT and IT an important mean for teaching as well as a new type of tools for learning. Since China has huge differences in its geographic, economic and educational level in different regions, the way that ICT and IT is being integrated in the system of professional trainings of teachers is diversified. In developed areas, such as Shanghai and Beijing, many educational authorities make full use of their advantages, conducting various kinds of ICT and IT education innovation activities that cultivate teachers` and teachers '-to-be problem-solving abilities by integrating ICT and IT education into classrooms. One-to-one e-learning, mobile education, miniature learning and digital whiteboard-based interactive learning are all new approaches of using ICT application in pedagogical teaching and learning process (Zhang, 2002).

Rural and less economically developed areas (as well as the ones geographically located far from big cities and popular touristic areas) face the problem of poor network connection that definitely influences the usage of ICT and IT education as learning and teaching method both for students and teachers. Also the Chinese government speaking about challenges for ICT and IT education in these regions found at least two categories of barriers tightly related to teachers' behavior: the lack of specific knowledge and skills about technology integration and attitudes and prejudice towards technology as a teaching method. Even many 
teachers have strong desires for integrating ICT and IT education into teaching, they encountered significant barriers, such as lacking confidence and competence, or having negative attitude and inherent resistance (mainly it concerns the teachers of the age over 40) (Wu, 2014).

Not only teachers' passive attitudes can cause barriers, but students can also pose challenges to ICT and IT education integration process. New generations, which are also called the Millennials, are much more skilled and adopted at using technology than their teachers. Under this circumstance, students have different patterns of thinking and communication, notions of learning, needs for control, and even personal and social values with their teachers. The same gab can be noticed in the educational institutions for teachers as well where about $68 \%$ of teaching staff is over 40 years old and especially in the retiree courses for teachers where about $80 \%$ of listeners and students obtain degrees and represent the generation of 45-55s (Hu \& Mc Grave, 2011).

In a nutshell, according to F. Miao (Miao, 2007) and M. Trucano (Trucano, 2012) today China faces IT teachers`education problems mainly of two kinds:

- $\quad$ psychological and educational one: teachers (especially working ones whose age is over 40) are psychologically not ready for huge amount of ICT (Miao, 2007);

- financial and technical one: technical weakness of the rural area schools makes usage of ICT as a practical method of teaching quite difficult (Trucano, 2012).

Also the researchers note, that the Chinese teachers, in particular, expressed more doubts about the effectiveness of using ICT applications in collaboration, independent learning and self-education. Moreover, Chinese teachers regard themselves more of an authority role when compared to Western teachers. The authority figure hinders the interactive use of ICT and IT education, as this is not consistent with the formal traditional education (Fu, 2017).

Effective support system is the key to quality online education. Effective support system for online education is traditionally seen to be consist of two categories: one for online educators and one for online learners. In China effective support services (an effective support system) for both categories is provided in cooperation with government agencies, educational institutions, private companies, families, society, etc. Unlike other countries (USA, France, Canada, Israel, Great Britain etc.) (Naidu, 2017) China does not does not accept the option of creating a support system for teachers or students from non-formal or public organizations (including NGOs) that do not cooperate with the state (in the person of the Ministry of Education or local government departments of education). The support of teachers is a priority for the Chinese state, since the system of work of the state (as well as of the society in general) with teachers as a category of civil 
Kalashnyk et al., 2021. Teachers`support service as a part of flexible education concept: experience of pr China

servants is guided by the ancient postulate "everything starts with a teacher and any troubles of the state can be prevented if children get appropriate education» (Li, 2019).

Today, the teachers` support service in China works in several areas:

Technical education of working teachers. Both teachers themselves and at the state level it is noted that today it is necessary to make efforts to improve the qualifications of teachers in the field of online learning, since most teachers are unfamiliar with the tools of synchronous and asynchronous education. In particular, such trainings should include online learning and information technology applications, examples of epidemic prevention measures in educational institutions and local teacher training, as this will contribute to the early development of teaching skills in the field of computer learning.

Methodical training of working teachers. Assistance to educators in this area includes training on how to use computer software for synchronous learning, how to use computer based learning management software, how to plan virtual training events, how to use online constructors, etc.

Legal assistance to working teachers. Much attention is also paid to legal issues of how to properly format links to video and audio materials that teachers take from the general Internet space, as well as how to protect their own copyrights to intellectual material, to which the lesson belongs. In most public schools, the rule was implemented that the rights to all developments made by teachers for conducting lessons on a school schedule belong to the educational institution, with the obligatory indication of the name of the teacher who created this or that lesson. In this case, the IT department of the educational institution is fully responsible for observing copyright and other legal issues related to online education.

Financial support for the online education process. The state undertook financing not only the technical aspects of the online education process (increasing the number of computers, IT courses for teachers, etc.), but also opened free online access to libraries and constructors, museums, exhibitions, etc., provided free a number of downloads and online minutes of communication in groups (including group conferences) for educational institutions, based on the number of teaching staff constantly involved in the provision of educational services. The Chinese Ministry of Education today coordinates 22 online learning platforms that offer a total of 24,000 free open online courses nationwide. Provincial schools and education companies also offer a huge selection of their own open learning resources.

Psychological assistance to working teachers. The main leitmotif of the administration's conversations with teachers, teachers' meetings, forums, etc. at the first stages of the transition of the educational process to the online was: "we 
will definitely cope and learn everything", "no one knows how to work ONLY online - this is normal, we will all learn everything all together" and the like. This position of the state and the administration made it possible not only to reduce, but practically to remove from teachers the feeling of anxiety, uncertainty and disappointment in their own abilities, etc. And the organization of practical support from the state and the educational institution (involving a large number of people to work over the lesson) significantly facilitated the daily routine of teaching classes and significantly reduced the level of fatigue and professionalemotional burnout of teachers in the country (Huang, Liu, Tlili, \& et al., 2020).

The Chinese state platform "National Cloud Classroom" (www.eduyun.cn) provides free use of electronic textbooks for subject teachers, compiled by education departments of various provinces (to familiarize teachers with the experience of different regions of China). Such electronic textbooks are widely used in various fields for teaching in all grades of junior and upper secondary schools. The educational platform for these schools also has a built-in collective authorship option that allows flexible curriculum development using, creating new classes using materials of the platform, create joint educational projects with teachers from different regions etc. The platform's functionality also includes support for lectures and interactive lessons.

At the same time, the Public Education Publishing House released the «Touching and Reading of PEP» mobile application, which contains free digital educational resources. During the implementation of the «Interrupted Studies, Lifelong Learning» initiative, the Ministry of Education demanded that education departments and educational institutions at all levels of education establish joint activities. The Ministry also called on various civil society organizations to actively offer the society more diverse and better educational resources (preapproved by specialized government agencies) (Huang, Liu, Tlili, \& etc., 2020).

China is committed to the position that in order to meet today's needs for online learning and to further develop this type of learning, public administrations of education need to take on many roles, such as leadership of educational policy, overall coordination and effective control of activities, including coordination of actions of private companies, educational institutions, research institutes, families, society, etc. to create stable communication platforms, select appropriate educational resources, provide convenient learning tools, support a variety of teaching methods and flexible teaching methods. An effective teacher support system in China is the result of close multilateral cooperation between the state and many actors in the country's social and economic life. 
Kalashnyk et al., 2021. Teachers`support service as a part of flexible education concept: experience of pr China

\section{Conclusions}

Unlike other countries (especially the ones of the former Soviet territory) the quarantine restrictments and study-at-home form of education did not much China due to self-organization of the Chinese teachers and students, thanks to technological readiness of the education system and the introduction of the idea of teachers support system (especially as to ICTs and ITs) and distance learning methods, which began long before COVID-19 pandemic. Also, own money at universities allowed them to sharply increase the number of technical personnel for organizing and maintaining the educational process in the new conditions. This allowed the entire education system in the PR China (from kindergartens to universities) quickly and entirely go into online space with minimal loss in the quality of educational services. Through the OUC system and other ICT sources were organized special training courses for teachers at rural areas to help them to adopt the new form of teaching. But as a result of the ICT revolution, which took place in the PR China's approaches to education in general back in the 2010s and the new paradigm of teacher training and support, compared with other countries, it did not lead to a boom in high technologies in the field of education in China. The main conclusion is can be noted: new education reality sets new requirements for the subject of the educational process (teacher), which cannot be satisfied by the teacher him/herself. To meet the needs of flexible education, a teacher starts to present the results of an integrated group's work, so called teachers` support service. This system of educational work organisation is rather expensive, but effective.

\section{References}

Baroutsis, A., McGregor, G., Mills, M., \& Riele, K. R. (2020). Teaching in Alternative and Flexible Education Settings, In A. Baroutsis, G. McGregor, M. Mills, \& Riele, K.R (Eds.).

Fu, W. (2017). ICT Integration in Chinese Basic Education System: From the Teaching and Learning Perspective. Zhejiang Shuren University Review, No.176, 17-22. (in Chinese)

Gordon, N. A. (2014). Flexible Pedagogies: technology-enhanced learning. The Higher Education Academy. Retrieved from https:/www.researchgate.net/publication/268741739_Flexible_Pedagogies_technology-enhanced_learning

Huang, R., Liu, D., Tlili, A., Yang, J., Van, H. etc. (2020). Handbook on Facilitating Flexible Learning During Educational Disruption: The Chinese experience in Maintaining Undisrupted Learning in COVID-19 outbreak. Beijing: SLIBNU.

Hu, Zh. \& McGrave, I. (2011). Innovation in higher education in China: are teachers ready to integrate ICT in English language teaching? Technology, Pedagogy and Education, No.20, 41-59.

Joan, R. (2013). Flexible learning as new learning design in classroom process to promote quality education. I-manager's Journal on School Educational Technology, 9, 1 (June). 
SOCIETY. INTEGRATION. EDUCATION

Proceedings of the International Scientific Conference. Volume V, May $28^{\text {th }}-29^{\text {th }}$, 2021. 116-126

Li, H. (2019). Chinese education system: history and nowadays. Shanghai public press. (in Chinese)

Miao, F. (2007). ICT Capacity standards for teachers in China. ICT in Teacher Education: Case Studies from the Asia-Pacific Region. Bangkok: United Nations Educational, Scientific and Cultural Organization (UNESCO), 53-62.

Naidu, S. (2017). Openness and flexibility are the norm, but what are the challenges? Distance Education, 38, 1-4.

Ryan, A., \& Tilbury, D. (2013). Flexible Pedagogies: new pedagogical ideas. Retrieved from http://www.heacademy.ac.uk/resources/detail/flexible-learning/flexiblepedagogies/ new_ped_ideas/report?utm_medium $=$ email\&utm_source $=$ The+Higher+Education+Academy\&u tm_campaign=4074096_140506\&utm_content=New-pedagogicalideas-report

Trucano, M. (2012). ICT and rural education in China. EduTech: a World Bank Blog on ICT use in education. Retrieved from: https://blogs.worldbank.org/edutech/ict-and-rural-education-in-china

Wu, D. (2014). An Introduction to ICT in Education in China. ICT in Education in Global Context: Lecture Notes in Educational Technology. Berlin, Heidelberg: Springer.

Xiaoqing, G., Yuankun, Zh., \& Xiaofeng, G. (2013). Meeting the "Digital Natives": Understanding the Acceptance of Technology in Classrooms. Educational Technology and Society, No.16 (1), 392-402.

Zhang, J. (2002). Incorporating ICT into K-12 Schools: China's Perspective in the Global Backgrounds, Tech Trends, Vol.46, Issue 4, 49-57. 